\title{
REZULTATI ISPITIVANJA MEŠAVINA ZEMLJE - PRVI IZVEŠTAJ
}

\author{
Ivan Hegediš ${ }^{1}$ \\ Čeh $\operatorname{Arpad}^{2}$ \\ Golub Karaman ${ }^{3}$ \\ Edita Tenji ${ }^{4}$ \\ Danilo Vunjak ${ }^{5}$
}

UDK: $691.41: 620.1$

DOI:10.14415/konferencijaGFS 2016.047

Rezime: Ispitivanje mešavina zemlje sa drugim prirodnim materijalima zasnovano na tradicionalnim iskustvima treba da pokaže kako se može preciznije pripravljati $i$ ugrađivati ova vrsta materijala uz manji utrošak energije i rada. Prva faza ispitivinja provedena je kroz seriju eksperimenata u sklopu laboratorijskih vežbi sa studentima $u$ okviru predmeta Tradicionalni materijali. Ispitivanje na velikom broju uzoraka pokazalo je da se komponovanjem različitih mešavina zemlje sa prirodnim dodacima organskog $i$ neorganskog porekla dobija građevinski materijal zavidnih karakteristika za primenu $u$ savremenim uslovima primneom tradicinalnih iskustava gradnje.

Ključne reči: zemlja, mešavina, prirodni dodaci

\section{UVOD}

Ispitivanje mešavina zemlje sa drugim prirodnim materijalima zasnovano na tradicionalnim iskustvima treba da pokaže kako se može preciznije pripravljati i ugrađivati ova vrsta materijala uz manji utrošak energije i rada. Prema planu ispitivanje se vrši u više faza ${ }^{6}$. Prva faza ispitivinja provedena je kroz seriju eksperimenata u sklopu laboratorijskih vežbi sa studentima u okviru predmeta Tradicionalni materijali. Izrađeno je i ispitano nekoliko stotina uzoraka različitih mešavina koji su grupisani po sastavu. U ovom izveštaju prikazani su rezultati za jednu grupu uzoraka.

\footnotetext{
${ }^{1}$ Dr Ivan Hegediš, dipl. inž. arh., Univerzitet u Novom Sadu, Građevinski fakultet Subotica, Kozaračka 2a, Subotica, Srbija, tel: 024554 300, e - mail: hege@tippnet.rs

${ }^{2}$ Arpad Čeh, dipl. inž. građ., Univerzitet u Novom Sadu, Građevinski fakultet Subotica, Kozaračka 2a, Subotica, Srbija, tel: 024554 300, e - mail: ceh@gf.uns.ac.rs

${ }^{3}$ Golub Karaman, dipl. inž. građ., Univerzitet u Novom Sadu, Građevinski fakultet Subotica, Kozaračka 2a, Subotica, Srbija, tel: 024554 300, e - mail: golub@gf.uns.ac.rs

${ }^{4}$ Edita Tenji, apsolvent, Univerzitet u Novom Sadu, Tehnološki fakultet, Novi Sad, Srbija, edit@tippnet.rs

${ }^{5}$ Danilo Vunjak, dipl.inž. građ., Institut za građevinarstvo i arhitekturu DOO, Kosančić Ivana 19, Novi Sad, Srbija, tel: 021/549-026, e - mail: danilovunjak@gmail.com
} 
Contemporary achievements in civil engineering 22. April 2016. Subotica, SERBIA

\section{SASTAV MEŠAVINA}

Kombinacija i količina mikroarmature je određivala i sastav i karakteristike uzoraka, kao i mogućnost primene za tradicionalnu gradnju, kako na našim prostorima, tako i šire. Mogućnost kombinacije zavisi od mesta ugradnje, raspoloživih materijala kao i potrebe za takvom vrstom gradnje i arhitektonskog uklapanja, ne remeteći tradicionalno okruženje.

Uzorci su spravljani tako da je glina mešana sa vodom te dodatkom organske mikroarmature (seno) i čestica neorganskog sastava (mleveni crep, lomljena keramika) kao i dodavanja humusa. Sastav uzoraka je prikazan u Tabeli 1:

Tabela 1. Sastavi ispitnih mešavina zemlje

\begin{tabular}{|c|c|c|}
\hline OZNAKE & $\begin{array}{l}\text { KORIŠĆENI } \\
\text { MATERIJAL }\end{array}$ & KOLIČINA (g) \\
\hline CG1 & $\begin{array}{l}\text { glina } \\
\text { voda } \\
\text { seno } \\
\end{array}$ & $\begin{array}{c}1700 \\
250 \\
1\end{array}$ \\
\hline $\mathrm{CG} 2$ & $\begin{array}{l}\text { glina } \\
\text { voda } \\
\text { seno }\end{array}$ & $\begin{array}{c}1700 \\
250 \\
2\end{array}$ \\
\hline CG5 & $\begin{array}{l}\text { glina } \\
\text { voda } \\
\text { seno }\end{array}$ & $\begin{array}{c}1700 \\
275 \\
5\end{array}$ \\
\hline CG10 & $\begin{array}{l}\text { glina } \\
\text { voda } \\
\text { seno }\end{array}$ & $\begin{array}{c}1700 \\
250 \\
10\end{array}$ \\
\hline HCG5 & $\begin{array}{l}\text { glina } \\
\text { humus } \\
\text { voda } \\
\text { seno }\end{array}$ & $\begin{array}{c}1500 \\
170 \\
230 \\
5 \text { (2cm dužine })\end{array}$ \\
\hline HCG10 & $\begin{array}{l}\text { glina } \\
\text { humus } \\
\text { voda } \\
\text { seno }\end{array}$ & $\begin{array}{c}1500 \\
170 \\
230 \\
10 \text { (2cm dužine) }\end{array}$ \\
\hline HCG5N & $\begin{array}{l}\text { glina } \\
\text { humus } \\
\text { voda } \\
\text { seno }\end{array}$ & $\begin{array}{c}1530 \\
170 \\
230 \\
5 \text { (5cm dužine })\end{array}$ \\
\hline HCG10N & $\begin{array}{c}\text { glina } \\
\text { humus } \\
\text { voda } \\
\text { seno }\end{array}$ & $\begin{array}{c}1530 \\
170 \\
230 \\
10 \text { (5cm dužine) }\end{array}$ \\
\hline CTG15N & $\begin{array}{c}\text { glina } \\
\text { mleveni crep } \\
\text { voda } \\
\text { seno }\end{array}$ & $\begin{array}{c}1530 \\
170 \\
300 \\
5 \text { (5cm dužine })\end{array}$ \\
\hline
\end{tabular}


Савремена достигнућа у грађевинарству 22. април 2016. Суботица, СРБИЈА

\begin{tabular}{|c|c|c|}
\hline CRG15N & glina & 1530 \\
& lomljeni crep & 170 \\
& voda & 300 \\
& seno & $5(5 \mathrm{~cm}$ dužine $)$ \\
\hline CTG55N & glina & 1615 \\
& lomljena keramika & 85 \\
& voda & 300 \\
& seno & $5(5 \mathrm{~cm}$ dužine $)$ \\
\hline CRG55N & glina & 1615 \\
& mleveni crep & 85 \\
& voda & 300 \\
& seno & $5(5 \mathrm{~cm}$ dužine $)$ \\
\hline
\end{tabular}

\section{PRIPREMA ME ̌̌AVINA}

U posudu je stavljena glina, nasuto seno, voda i ostali dodaci. Svi materijali su mešani dok se smesa nije sjedinila. Dobijena smesa stavljena je u kalupe, nabijena i poravnata sa gornje strane. Kalup je stavljen u pećnicu na temperaturi od $50^{\circ} \mathrm{C}$ (Slika 1.). Nakon toga se vrši ispitivanje dela dobijenih uzoraka u laboratoriji, a preostali deo se ostavlja da odleži u različitim vremenskim uslovima. Nakon određenog vremena, predviđenog planom ispitivanja (nakon 90 dana), možemo nastaviti ispitivanje i utvrditi karakteristike tako izloženih materijala u prirodnom okruženju, kao i nastaviti daljna istraživanja tokom protoka vremena.
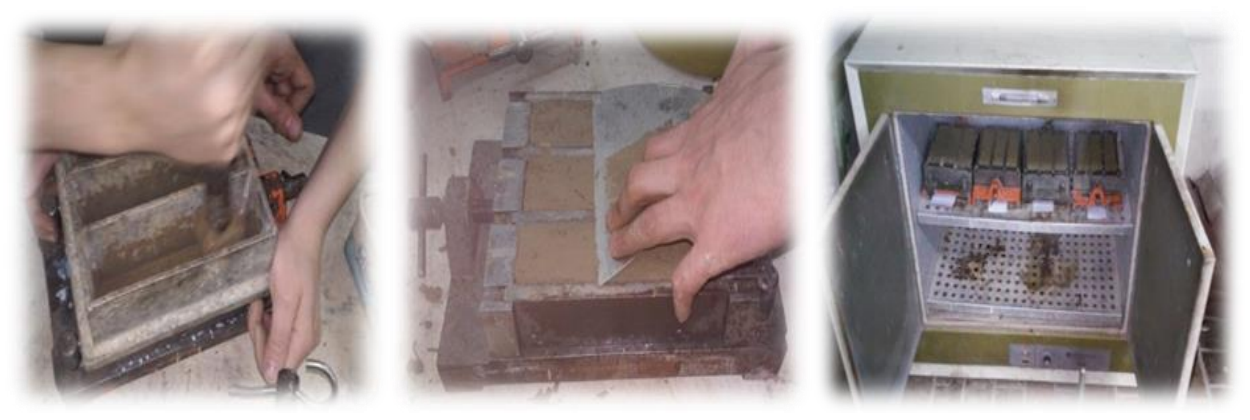

Slika 1. Nabijanje smeše u kalupe, ravnanje gornje površine i stavljanje svih kalupa $u$ pećnicu

\section{REZULTATI}

Nakon 90 dana na po 3 uzorka iz svake serije je ispitana zapreminska masa, vlažnost, čvrstoća pri zatezanju savijanjem i čvrstoća pri pritisku, rezultati su dati u Tabeli 2: 
Contemporary achievements in civil engineering 22. April 2016. Subotica, SERBIA

Tabela 2. Rezultati ispitivanja uzoraka držanih na $20{ }^{\circ} \mathrm{C}$ i RH 50\% pri starosti od 90 dana

\begin{tabular}{|c|c|c|c|c|}
\hline & $\begin{array}{c}\text { Zapreminska } \\
\left.\text { masa [g/cm }{ }^{3}\right]\end{array}$ & $\begin{array}{c}\text { Absolutna } \\
\text { vlažnost [\%] }\end{array}$ & $\begin{array}{c}\text { Čvrstoća pri } \\
\text { zatezanju } \\
\text { savijanjem [MPa] }\end{array}$ & $\begin{array}{c}\text { Cvvrstoća pri } \\
\text { pritisku } \\
\mathrm{f}_{\mathrm{P}}[\mathrm{MPa}]\end{array}$ \\
\hline CG1 & 1,72 & 1,8 & 1,49 & 3,06 \\
\hline CG2 & 1,7 & 1,87 & 1,12 & 3,25 \\
\hline CG5 & 1,72 & 1,81 & 0,19 & 3,63 \\
\hline CG10 & 1,75 & 1,41 & 0,19 & 3,00 \\
\hline HCG5N & 1,69 & 1,62 & 0,19 & 3,06 \\
\hline HCG10N & 1,75 & 1,71 & 1,15 & 3,25 \\
\hline HCG10 & 1,7 & 1,61 & 0,19 & 2,94 \\
\hline HCG5 & 1,74 & 1,63 & 1,38 & 2,94 \\
\hline CRG15N & 1,66 & 1,63 & 0,46 & 1,88 \\
\hline CTG55N & 1,72 & 1,35 & 0,69 & 2,94 \\
\hline CRG55N & 1,62 & 1,5 & 0,69 & 2,06 \\
\hline CTG15N & 1,62 & 1,31 & 0,69 & 1,69 \\
\hline
\end{tabular}

Pri starosti od 90 dana su 3 uzorka iz svake grupe stavljeni u sušaru, gde su potpuno osušeni na $105^{\circ} \mathrm{C}$. Nakon vađenja iz sušare i hlađenja do temperature uzoraka od cca, $20^{\circ} \mathrm{C}$, izmerena je njihova masa i ispitana je njihova čvrstoća pri pritisku (Tabela 3):

Tabela 3. Rezultati ispitivanja osušenih uzoraka pri starosti od 90 dana

\begin{tabular}{|c|c|c|c|c|}
\hline & $\begin{array}{c}\text { Zapreminska } \\
\text { masa }\left[\mathrm{g} / \mathrm{cm}^{3}\right]\end{array}$ & $\begin{array}{c}\text { Čvrstoća pri } \\
\text { zatezanju } \\
\text { savijanjem }[\mathrm{MPa}]\end{array}$ & $\begin{array}{c}\text { Čvrstoća pri } \\
\text { pritisku } \\
\mathrm{f}_{\mathrm{P} 0}[\mathrm{MPa}]\end{array}$ & $\begin{array}{c}\text { Odnos čvrstoća } \\
\text { pri pritisku } \\
\mathrm{f}_{\mathrm{P}} / \mathrm{f}_{\mathrm{P} 0}\end{array}$ \\
\hline CG1 & 1,68 & 1,84 & 5,78 & 0,53 \\
\hline CG2 & 1,67 & 2,06 & 7,71 & 0,42 \\
\hline CG5 & 1,69 & 2,30 & 7,43 & 0,48 \\
\hline CG10 & 1,73 & 2,30 & 6,21 & 0,48 \\
\hline HCG5N & 1,66 & 1,72 & 6,56 & 0,46 \\
\hline HCG10N & 1,72 & 2,07 & 4,12 & 0,78 \\
\hline HCG10 & 1,67 & 2,30 & 5,25 & 0,56 \\
\hline HCG5 & 1,71 & 2,30 & 6,0 & 0,49 \\
\hline CRG15N & 1,63 & 1,83 & 3,93 & 0,47 \\
\hline CTG55N & 1,69 & 1,83 & 3,93 & 0,74 \\
\hline CRG55N & 1,60 & 1,60 & 4,25 & 0,48 \\
\hline CTG15N & 1,60 & 0,69 & 1,69 & 1,69 \\
\hline
\end{tabular}

Treći set od 3 uzoraka iz svake grupe je bila izložena u klima-komori naizmeničnom mržnjenju na $-20^{\circ} \mathrm{C} 5$ sati i kravljenju na $+25^{\circ} \mathrm{C}$ pri relativnoj vlažnosti sredine od $95 \%$ takođe 5 sati. Nakon 2 takva ciklusa na uzorcima sa približnom temperaturom od $+25^{\circ} \mathrm{C}$ je izmerena je njihova masa $\mathrm{i}$ ispitana je njihova čvrstoća pri pritisku. U Tabeli 4. je pored navedenog data i promena čvrstoće pri pritisku nakon 2 ciklusa mražnjenja i kravljenja u odnosu na rezultate uzoraka iz normalne sredine. 
4.

МЕЂУНАРОДНА КОНФЕРЕНЦИЈА

Савремена достигнућа у грађевинарству 22. април 2016. Суботица, СРБИЈА

Tabela 4. Rezultati ispitivanja uzoraka izloženih mražnjenju pri starosti od 90 dana

\begin{tabular}{|c|c|c|c|c|}
\hline & $\begin{array}{c}\text { Zapreminska } \\
\text { masa [g/cm }\end{array}$ & $\begin{array}{c}\text { Absolutna } \\
\text { vlažnost }[\%]\end{array}$ & $\begin{array}{c}\text { Čvrstoća pri } \\
\text { pritisku } \mathrm{f}_{\mathrm{P}}{ }^{*}[\mathrm{MPa}]\end{array}$ & $\begin{array}{c}\text { Odnos čvrstoća } \\
\text { pri pritisku } \mathrm{f}_{\mathrm{P}}{ }^{*} / \mathrm{f}_{\mathrm{P} 0}\end{array}$ \\
\hline CG1 & 1,76 & 0,98 & 2,56 & 0,84 \\
\hline CG2 & 1,74 & 0,93 & 2,62 & 0,81 \\
\hline CG5 & 1,67 & 0,97 & 4,37 & 1,21 \\
\hline CG10 & 1,69 & 1,15 & 3,62 & 1,21 \\
\hline HCG5N & 1,59 & 1,0 & 3,75 & 1,22 \\
\hline HCG10N & 1,89 & 1,05 & 3,06 & 0,94 \\
\hline HCG10 & 1,87 & 1,05 & 2,63 & 0,9 \\
\hline HCG5 & 1,85 & 1,04 & 4 & 1,36 \\
\hline CRG15N & 1,69 & 0,95 & 2,22 & 0,56 \\
\hline CTG55N & 1,72 & 0,95 & 2,38 & 0,81 \\
\hline CRG55N & 1,74 & 0,92 & 2,06 & 1,0 \\
\hline CTG15N & 1,65 & 0,94 & 2,43 & 1,44 \\
\hline
\end{tabular}

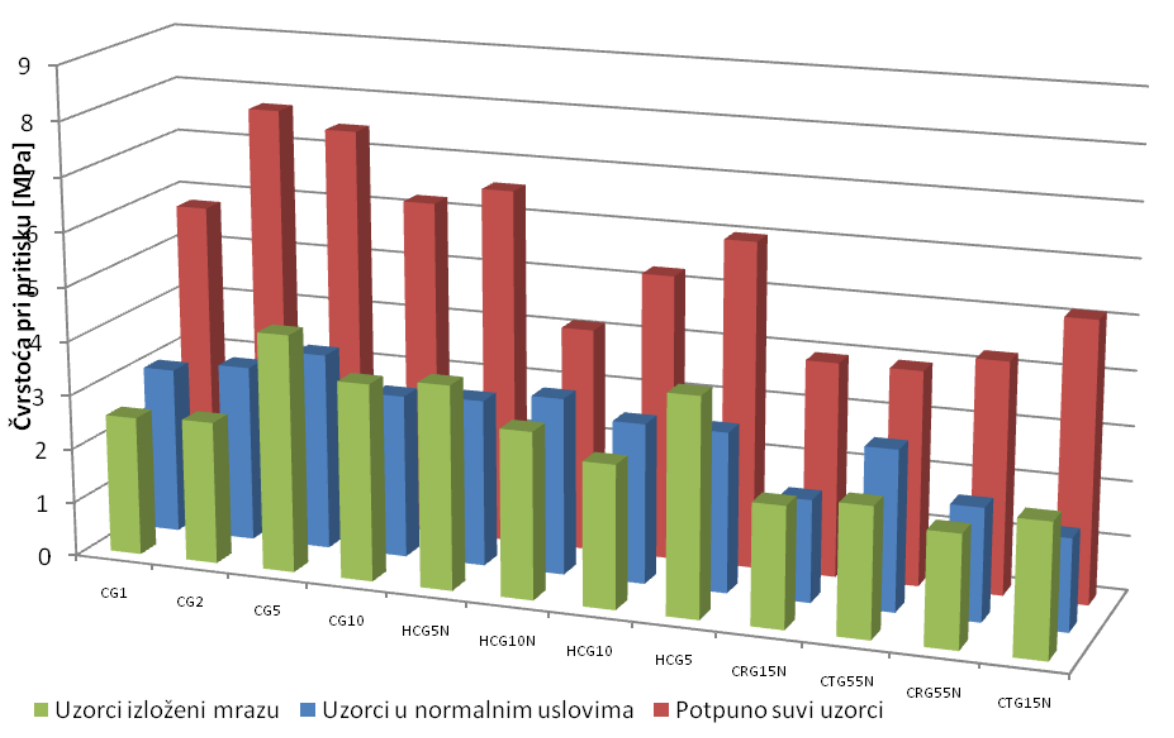

Slika 2. Pritisne čvrstoće svih uzoraka u različitim uslovima sredine

\section{ZAKLJUČAK}

Karakteristike pojedinih uzoraka vezane za čvrstoću pri pritisku, čvrstoću na zatezanje pri savijanju, zapreminsku masu, kako u suvom, tako i u vlažnom stanju direktno zavise od vlažnosti (kao opštem nedostatku ovog materijala) ali i od količine i vrste dodataka koji značajno menjaju svojstva. Raznim kombinacijama mikrovlakana sa priručnim materijalom, možemo napraviti mešavinu koja odgovara datom mestu gradnje, zbog autohtonih materijala, sastava zemljišta i uslova gradnje. 
Contemporary achievements in civil engineering 22. April 2016. Subotica, SERBIA

Svakako da moramo imati u vidu sastav zemlje kao osnovnog materijala, na osnovu koga možemo poboljšavati karakteristike mešavine dodatkom različitih organskih i neorganskih mirovlakana, a to nam daje pretpostavku da napravimo materijal kakav odgovara tom podneblju i zbog toga što je građenje zemljom opravdano samo $u$ lokalnim uslovima, jer je transport na veće daljine neekonomičan. Iz tog razloga i ovo naše spravljanje i ispitivanje različitih mešavina ide u prilog opravdanosti gradnje na samom pozajmištu zemlje kao osnovnog materijala i mikroarmature iz okoline, kao i prirodnim uslovima tokom gradnje i eksploatacije objekata.

\section{LITERATURA}

[1] A. N. Gramlich: A concise history of the use of the rammed earth building technique including information on methods of preservation, repair, and maintenance, Graduate School of the University of Oregon, 2013

[2] J. Canivell, A. Graciani: Critical analysis of interventions in historical rammed-earth walls-military buildings in the ancient Kingdom of Seville, Seville University, Seville, Spain,

[3] D. M. Escobar: Earth architecture, building with rammed earth in a cold climate, Chalmers, University of Technology, Gothenburg, Sweden, 2013

[4] G. Minke: Building with Earth, Design and Technology of a Sustainable Architecture, Birkhäuser - Publishers for Architecture, Basel, Berlin, Boston, 2006

[5] G. T. Ciurileanu, I. B. Horvath: The use of cement stabilized rammed earth for building a vernacular modern house, Technical University of Cluj-Napoca, Received: February 15, 2012

[6] E. W. Simenson: Rammed earth: Fiber-reinforced, cement stabilized, B.S., University of Colorado Denver, 2011

[7] C. Zhou1,Y. Liang: Review on technics of rammed earth wall, School of Architecture, Fuzhou University, Fuzhou, Fujian 350108, P.R. China

\section{RESULTS OF TESTING EARTH MIXTURES - FIRST REPORT}

Summary: Testing the mixtures of earth with other natural materials based on traditional experience should demonstrate how they can be improved and built in using less energy and more effective. The first phase of testing was conducted through a series of experiments in the laboratory practice classes with students within the subject of traditional materials. Testing on a large number of specimens showed that different mixes of earth with natural additives of organic and inorganic origin can result a building material of enviable characteristics suitable to use in modern conditions incorporating traditional experiences of construction.

Keywords: earth, mixtures, natural additives 